\title{
Off-label use of common predictive biomarkers in gastrointestinal malignancies: a critical appraisal
}

\author{
Basile Tessier-Cloutier ${ }^{1,2+}$ (D), Ellen Cai ${ }^{1,2+}$ and David F. Schaeffer ${ }^{1,2^{*}}$
}

\begin{abstract}
The use of immunohistochemistry (IHC) as a companion diagnostic is an increasingly important part of the case workup by pathologists and is often central to clinical decision making. New predictive molecular markers are constantly sought for to improve treatment stratification parallel to drug development. Unfortunately, official biomarker guidelines lag behind, and pathologists are often left hesitating when medical oncologists request offlabelled biomarker testing. We performed a literature review of five commonly requested off-label IHC predictive biomarkers in gastrointestinal tract (GIT) malignancies: HER2, mismatch repair (MMR), PD-L1, BRAF V600E and ROS1. We found that HER2 amplification is rare and poorly associated to $I H C$ overexpression in extracolonic and extragastric GIT cancers; however in KRAS wild type colorectal cancers, which fail conventional treatment, HER2 IHC may be useful and should be considered. For MMR testing, more evidence is needed to recommend reflex testing in GIT cancers for treatment purposes. MMR testing should not be discouraged in patients considered for second line checkpoint inhibitor therapy. With the exception of gastric tumors, PD-L1 IHC is a weak predictor of checkpoint inhibitor response in the GIT and should be replaced by MMR in this context. BRAF inhibitors showed activity in BRAF V600E mutated cholangiocarcinomas and pancreatic carcinomas in non-first line settings. ROS1 translocation is extremely rare and poorly correlated to ROS1 IHC expression in the GIT; currently there is no role for ROS1 IHC testing in GIT cancers. Overall, the predictive biomarker literature has grown exponentially, and official guidelines need to be updated more regularly to support pathologists' testing decisions.
\end{abstract}

Keywords: Gastrointestinal tract cancer, HER2, MMR, PD-L1, BRAF V600E, ROS1, Immunohistochemistry, Predictive biomarkers

\section{Introduction}

The first immunohistochemistry (IHC) methods were developed in the 1930s, and as the technology evolved it quickly became a clinical standard in the 80 s. Since then, there has been a vast increase in publication involving IHC techniques. Today, IHC is routinely used to support diagnosis and to guide treatment but as sequencing techniques become more available for directing personalized treatment, the overlap between the two technologies can cause confusion. Although many clinically useful genomic features can be detected using both IHC

\footnotetext{
* Correspondence: David.Schaeffer@vch.ca

${ }^{+}$Basile Tessier-Cloutier and Ellen Cai contributed equally to this work.

${ }^{1}$ Department of Pathology and Laboratory Medicine, University of British Columbia, Vancouver, BC, Canada

${ }^{2}$ Department of Pathology and Laboratory Medicine, Vancouver General Hospital, 910 West 10th Ave, Vancouver, BC, Canada
}

and DNA/RNA sequencing, clinical validation of genomic assays is still often lacking. Moreover, IHC instruments are ubiquitous among pathology laboratories and the cost of developing and running IHC assays is inexpensive and fast compared to the emerging next generation sequencing assays.

As part of the personalized medicine revolution, many cancers, including gastrointestinal malignancies, can be tested for biomarkers that are predictive of response to a targeted therapy. Current recommendations from the College of American Pathologists include HER2 IHC in esophageal and gastric adenocarcinomas, MMR IHC in colorectal and gastroesophageal adenocarcinomas and BRAF V600E IHC in colorectal adenocarcinomas only. [1-3] Results from basket and umbrella trials, comprehensive genomic analyses and even isolated case reports

(c) The Author(s). 2019 Open Access This article is distributed under the terms of the Creative Commons Attribution 4.0 International License (http://creativecommons.org/licenses/by/4.0/), which permits unrestricted use, distribution, and 
sometimes show benefit in off-label testing and treatment. $[4,5]$ Unfortunately guidelines take time to be updated and it is increasingly common for medical oncologists, sometimes pressured by their patients, to request off-label IHC testing.

Since the surgical pathologist is responsible for the interpretation of IHC, the decision to perform a test not yet supported by clinical guidelines can be challenging. Even thorough review of the literature may not give clear direction, and the hesitation surrounding off-label testing is time consuming; therefore, there is possibility for misinterpretation. To aid decision making in situations where human epidermal growth factor receptor 2 (HER2), mismatch repair proteins (MMR), programmed death-ligand 1 (PD-L1), BRAF V600E and ROS1 IHC biomarkers are considered in gastrointestinal malignancies, we reviewed the literature and offer recommendations on an algorithmic approach to these biomarkers in the digestive tract. We created decision trees for each of the gastrointestinal sites to help visualize our conclusions by representing the degree of evidence as high (official management guidelines, in green), intermediate (clinical trials, in yellow), low (case series, case reports, retrospective reviews, in dark grey) and no evidence (in pale grey) (Fig. 1).
HER2

The ERBB2/HER2 gene, which encodes a transmembrane glycoprotein receptor, was at the center of the personalized medicine revolution in the early $2000 \mathrm{~s}$. When this gene is amplified, high levels of HER2 cell surface receptors quickly becomes the main driver for tumor progression. A recombinant monoclonal antibody, trastuzumab, was developed to recognize HER2 and trigger antibody-dependent cellular cytotoxicity; it inhibits HER2-mediated signaling, and prevents cleavage of the extracellular domain of HER2. [6, 7] In breast cancer and gastroesophageal cancers overexpressing HER2, trastuzumab has shown a survival advantage in early and metastatic disease and is now the standard of care. $[1,8]$

Within GIT tumor types, HER2 expression is well described in colorectal and gastroesophageal adenocarcinomas; it is successfully targeted by HER2 specific tyrosine kinase inhibitors. $[9,10]$ With up to $5 \%$ amplification rate in colon cancer, the HERACLES trial showed high rates of response and prolonged disease control from HER2 targeted treatment in an otherwise treatment resistant group. This trial with other supporting evidence offer an explanation for potential mechanisms of resistance to HER2 kinase inhibitors, which is through

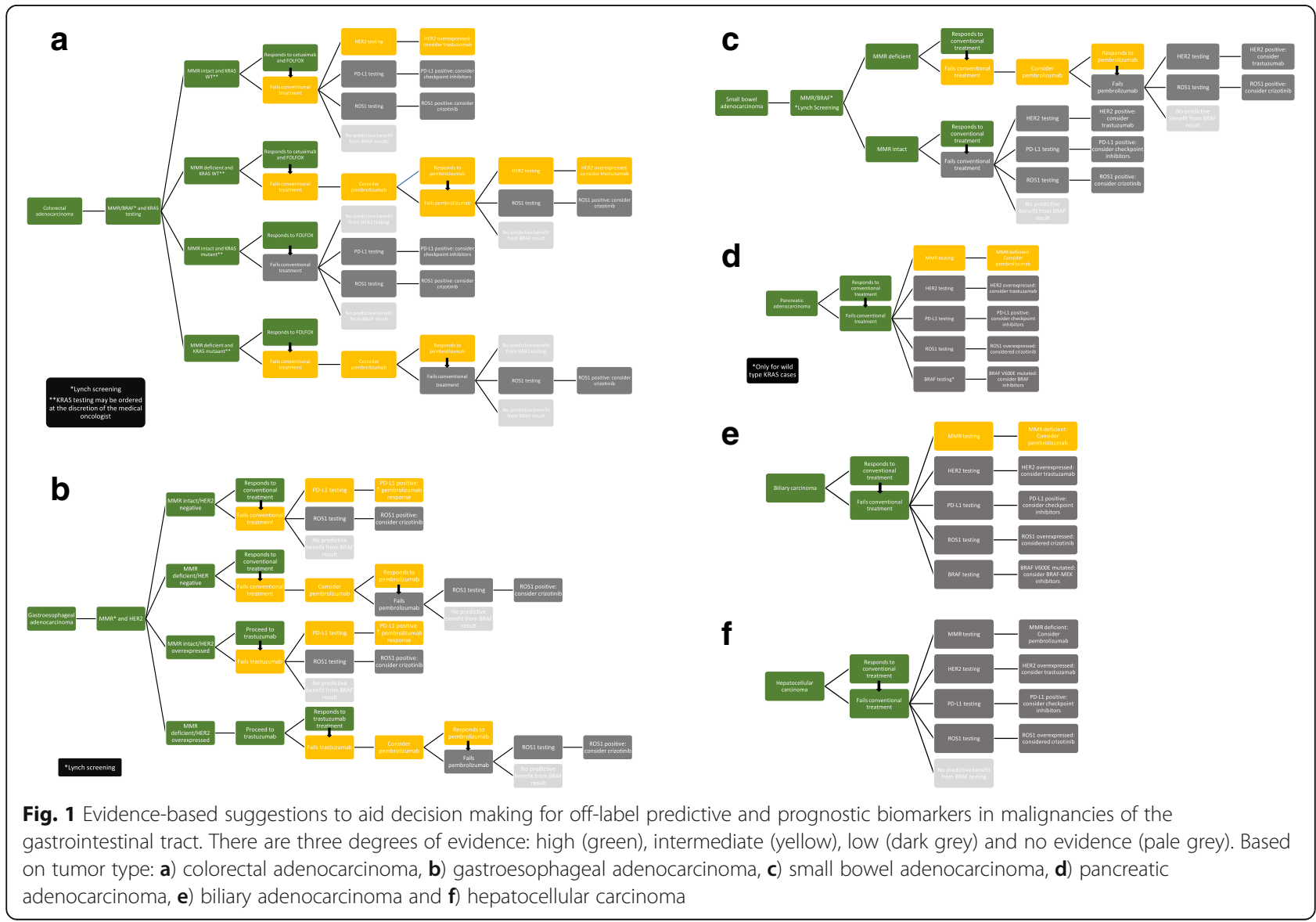


KRAS inactivating mutations or other RAS pathway alterations. $[9,11,12]$ Based on this evidence, we do not recommend HER2 testing in these KRAS mutated cases.

In other GIT sites, HER2 amplification is uncommon. Although one IHC and fluorescent in-situ hybridization (FISH) systematic review showed common overexpression and amplification with rates up to 28 and $23 \%$, respectively, in hepatobiliary cancers such as ampullary carcinomas, extrahepatic biliary tract cancers, gallbladder carcinomas and extrahepatic cholangiocarcinomas, most other GIT cancers studies report overexpression rates below 10\%. [13-21] In large scale next generation sequencing (NGS) data from the MSK-IMPACT trial, amplifications were rare: $0 \%$ in small bowel cancer $(n=$ $35), 1.8 \%$ in pancreatic carcinomas $(n=502)$ and $3.4 \%$ in hepatobiliary cancers $(n=355)$. [22] It is unclear as to why the rates of amplification between FISH and NGS panels are so different, but race may be a factor since the FISH studies showing the high rates of amplification were based in Asia.

No clinical trials thus far have directly assessed the potential of HER2 inhibitors against HER2 amplified extracolonic/gastric GIT cancers. A cohort of patient-derived mouse xenograft benefited from cetuximab and trastuzumab over gemcitabine for the treatment of human pancreatic cancer; however, in a cohort of pancreatic cancer patients, a clinical trial assessing trastuzumab (not tested for HER2 amplification) showed no significant response. $[23,24]$ There is one anecdotal report of a HER2 amplified small bowel adenocarcinoma that displayed durable response to trastuzumab as second line therapy. [25] This finding is consistent with data in colorectal carcinoma (CRC) which exhibits activity from HER2 inhibitors. $[9,26]$

There are no indications for HER2 IHC reflex testing in extracolonic and extragastric GIT carcinomas. The rates of $1-3 \%$ amplification could be worth investigating, especially for commonly unresponsive diseases like pancreatobiliary carcinomas, but the yield of large-scale reflex testing is unknown since no trials have shown benefit from HER2 inhibitors yet. Moreover, the relationship between HER2 gene amplification and HER2 protein overexpression by IHC and their predictive potential are still unclear in these tumor types.

\section{Mismatch repair proteins}

Mismatch repair (MMR) is an extremely well conserved mechanism across species that focusses on correcting DNA replication errors, especially in repetitive DNA sequences like microsatellites. MMR deficiency, defined by the loss of function in MSH2, MSH6, MLH1 or PMS2, typically causes microsatellite instability (MSI), which is associated with higher tumor antigenicity and response to programmed death 1 (PD-1) blockade. [4] MMR deficiency can result from a germline mutation (Lynch syndrome), a somatic mutation, or epigenetic promoter silencing. Alternatively, MSI can also be estimated using a polymerase chain reaction (PCR) based assay traditionally screening for events in 5 microsatellite loci. Depending on the number of regions showing alterations, a tumor is either define as MSI-high or MSI-low. [27]

In extracolonic malignancies, MMR deficiency is most common in small bowel adenocarcinomas (13-35\%), hepatocellular carcinoma $(22 \%)$ and pancreatic adenocarcinomas (15\%). [13, 19, 28-33] In Barrett-esophagus associated adenocarcinomas, gastric carcinomas, and cholangiocarcinomas the loss of staining in MMR ranges from $0 \%$ to up to $10.9 \%$, where it is generally also associated with longer survival. [28, 34-41]

In May 2017, for the first time in its history, the U.S. Food and Drug Administration approved a targeted therapy agnostic of site. Indeed, the results from Dung Le showed that MMR deficiency by IHC predicted response to pembrolizumab in 12 different malignancies including gastroesophageal, small bowel, pancreatobiliary and colorectal cancers, likely acting as a surrogate for high tumor mutational burden. [4, 42] Currently, any metastatic solid MMR deficient tumors which failed first line treatment can be considered for PD-1 blockade therapy. The study also observed that PD-L1 IHC status was not significantly associated with progression-free survival or overall survival.

In gastric cancer patients the MAGIC trial showed that MMR deficiency is associated with shorter survival when treated with surgery and adjuvant chemotherapy, but cases treated with surgery alone, MMR deficiency is associated with better prognosis. This trial was the first to suggest that loss of MMR function might be a predictor of poor response to perioperative epirubicin, cisplatin, and fluorouracil chemotherapy. [30]

Overall, MMR is now established as a predictive marker for response to pembrolizumab, with other checkpoint inhibitors are likely to follow. In this context testing for MMR should not be discouraged for metastatic tumors failing first line treatment. As discussed above MMR deficient tumors represent a significant portion of GIT cancers and accordingly, we can expect MMR IHC to be requested regularly in this demographic. Unlike some evidence that PD-L1 expression may increase following cytotoxic therapy, more research is needed to evaluate the effect of treatment on MMR and MSI status. [43] Until then we suggest testing metastatic tumor over primary tissue when available. It is also unclear if extracolonic cases showing MMR deficiency should be directly referred to a medical geneticist for Lynch syndrome work up, or if different guidelines should be applied since the association between MMR loss and Lynch syndrome is not as strong in these tumor types. 
PD-L1

With the emergence of immune checkpoint inhibitors, increasing interest has been placed on identifying a predictive biomarker for response. PD-L1 IHC was the first biomarker to show predictive potential in the initial checkpoint inhibitor trials. [44] This IHC targets the ligand, present on both tumor cells and lymphocytes, which interacts with the PD-1 receptor to suppress the immune response. [45] In lung adenocarcinomas PD-L1 IHC positivity is a pre-requisite for certain immune checkpoint inhibitor treatment, but for CRC, MMR status, acting as a surrogate for tumor mutational burden, is the preferred predictive biomarker as discussed above. $[42,46]$ Apart from its role in lung adenocarcinomas, PD-L1 is still under investigation as both a predictive and prognostic biomarker in other GIT malignancies with microsatellite stable profiles. [47]

PD-L1 IHC expression is common in GIT tumors and although it was often hypothesized to be a surrogate for high tumor mutational burden, similarly to MMR deficiency, a recent study on lung cancer suggest that they may in fact be uncorrelated. [48] The prognostic value of PD-L1 IHC expression is controversial. In previous studies, it did not show significant prognostic role in esophageal adenocarcinomas, but is favorable in squamous cell carcinoma of the esophagus. [49-51] Esophageal cancers showing epithelial-mesenchymal transition had higher PD-L1 expression. $[50,52]$ In gastric cancer it has been associated with microsatellite instability and a worse prognosis, whereas in pancreatic cancers, studies cannot reach consensus with regards to its prognostic prediction. [53] In both extrahepatic and intrahepatic biliary carcinomas, PD-L1 expression has been associated with worse prognosis. [54,55] The mixed results of of the PD-L1 IHC across different tumor site could be explained by the different type of antibodies used, as well as patient selection.

In Keynote-059, PD-L1 IHC was used on a cohort of advanced gastric and gastroesophageal junction carcinomas prior to being treated with pembrolizumab. The expression recorded as positive if the combined positive score (ie. number of PD-L1-positive cells [tumor cells, macrophages, lymphocytes] divided by the total number of tumor cells, multiplied by 100) was greater than 1 . In cohort 1 (pembrolizumab monotherapy as 3rd line), the PD-L1 positive patients' $(15.5 \%, 16.3$ months) response rate and duration was over twice that of the PD-L1 negative group $(6.4 \%, 6.9$ months). [56] In cohort 2 (pembrolizumab-chemotherapy combination as first line), the observed response rate was higher in the PDL1 positive group (68.8\%) compared to the PD-L1 negative group (37.5\%). [57] In other GIT cancers PD-L1 expression has not yet been prospectively tested as a predictive biomarker for checkpoint inhibitors. All GIT tumor, including CRC, tested in the initial pembrolizumab trial showed no benefit from therapy. [44] Further studies showed that tumor stratification based on PD-L1 expression or mutational load surrogate, improved the rate of response to checkpoint inhibitors but lacks sensitivity. $[4,58,59]$ To date, this relationship in extracolonic GIT tumors remains mostly unexplored, let alone the percentage of tumor staining thresholds and the ideal antibody clone. Moreover, the amount of tumor tissue necessary to account for PD-L1 heterogenous expression needs to be established to consider its use in biopsy specimens.

\section{BRAF}

Activating BRAF mutation, especially V600E, is a common mechanism for the constitutive activation of the MAP-kinase pathway, which has been observed in various malignancies. [60, 61] In metastatic melanomas, BRAF inhibitors have revolutionized treatment of many $B R A F$ mutated tumors; however in CRC, BRAF inhibitors failed to show any benefits. [62, 63] BRAF V600E IHC is a readily available surrogate for the most common $B R A F$ mutation, and is now evaluated as a predictive biomarker in other tumor types. $[64,65]$

Multiple studies have investigated the incidence of $B R A F$ V600E mutations in extracolonic gastrointestinal tumors and all showed dismal rates $(<1 \%)$. [66-76] The only extracolonic GIT sites that showed marginally higher frequency of $B R A F$ mutations are cholangiocarcinomas (1.3\%), and KRAS wild-type pancreatic adenocarcinomas $(0-3 \%)$. [77-80] Case reports and now recently published preliminary results from the ROAR clinical trial show that metastatic $B R A F$ mutant biliary tract cancers might benefit from BRAF and MEK inhibitors treatment. [81-83] As for pancreatic cancers, a recent case series of two metastatic BRAF mutated pancreatic adenocarcinomas (V600E and V600_601delinsG), suggested some benefit from BRAF inhibition. [84] We propose that off-label BRAF V600E testing can be performed for metastatic cholangiocarcinoma and KRAS wild type pancreatic adenocarcinomas in the non-first line setting. In other extracolonic GIT malignancies, currently there is no evidence for BRAF V600E IHC testing given the lack $B R A F$ mutations and the lack of existing evidence for response to BRAF inhibition therapy.

\section{ROS1}

ROS1 is a known oncogene coding for a receptor tyrosine kinase that, similarly to the anaplastic lymphoma kinase (ALK), belongs to the insulin receptor superfamily. [85] The constitutive activation of ROS1 from chromosomal rearrangements is well established in lung adenocarcinomas and is associated with durable response to crizotinib. [86, 87] The ROS1 IHC has shown 
good concordance with FISH and reverse transcription polymerase chain reaction (RT-PCR) assays in lung adenocarcinoma and is used routinely in some pathology laboratories as a predictive biomarker for crizotinib.

One study quoted 9\% ROS1 fusion from a phosphorylation assay using mass spectrometry, but NGS assays only found rare ROS1 fusion in GIT cancers. [88] Based on data from The Cancer Genome Atlas (TCGA) and MSK-IMPACT trial, gastroesophageal cancers have a ROS1 fusion rate of $2.6 \%(n=341)$ and pancreatic carcinomas have a rate of $0.2 \%(n=502)$. No fusion was identified in cholangiocarcinomas $(n=355)$ and CRC $(n=1007)$. [22, 89] The mass spectrometry results need to be confirmed using more conventional sequencing methods tailored to ROS1 fusion detection in GIT malignancies.

The ROS1 IHC has shown good sensitivity and specificity as a surrogate marker for ROS1 rearrangement in lung adenocarcinomas [90-95], but recent studies showed much lower specificity in gastric adenocarcinomas (3/23) and cholangiocarcinomas (0/72) when compared to NGS assays. [96, 97] So far there is no report of ROS1 inhibitors being used in cholangiocarcinomas and the potential use of ROS1 IHC expression for prognostic purposes is unclear. Two retrospective studies looking at survival based on ROS1 IHC showed opposing results, one suggested better prognosis and histologic differentiation and the other a worse prognosis. $[97,98]$ Tumors with low expression in ROS1, ALK, and c-MET IHC were associated with better response to a combination of gemcitabine, oxaliplatin and cetuximab, than those with high expression of ROS1, ALK and c-MET. [98]

Overall the data on ROS1 in extracolonic cancers is sparse. Despite the increasing interest in targeted therapy in the rare cases with ROS1 rearrangement, the poor concordance between IHC overexpression and the fusion supports no role for universal screening for ROS1 alterations with ROS1 IHC in GIT malignancies.

\section{KRAS}

KRAS mutation testing has shown to be an important predictive marker in colorectal carcinomas. [99-101] It is unclear if the decision to perform KRAS testing should be driven by the responsible pathologist or be requested by the treating medical oncologist. For the purpose of this review we excluded KRAS from the decision algorithms.

\section{Conclusion}

In conclusion, the evolution of predictive biomarkers in diagnostic oncology is rapidly outpacing the established clinical guidelines, and pathologists will encounter increasing off-label testing requests. Substantial evidence supports screening for MMR deficiency in GIT adenocarcinomas and HER2 overexpression in colorectal adenocarcinomas when alternative treatment is needed. That said, there is an obvious need for evidence-driven testing algorithms and established roles for medical and diagnostic oncologists, so that predictive and prognostic biomarker testing can be optimized. Currently it is up to the pathologist to assess if a requested off-label test is appropriate based on his or her knowledge of the clinical context. In the absence of more regular guideline updates, review papers can be of great aid to the pathologist with evidence-based recommendations.

\section{Acknowledgements \\ N/A}

\section{Authors' contributions}

All authors participated on the design of the review, the review of literature and manuscript preparation. All authors read and approved the final manuscript.

\section{Funding}

Intradepartmental funding only (Department of Pathology and Laboratory Medicine, Vancouver General Hospital, Vancouver).

\section{Availability of data and materials}

N/A, no new patient data presented.

Ethics approval and consent to participate

N/A, no new patient data presented.

\section{Consent for publication}

$\mathrm{N} / \mathrm{A}$, no new patient data presented.

\section{Competing interests}

DFS declares to receive consulting fees from Robarts Clinical Trials Inc. and honoraria from Amgen Canada.

Received: 28 March 2019 Accepted: 11 June 2019

Published online: 21 June 2019

References

1. Bang YJ, Van Cutsem E, Feyereislova A, Chung HC, Shen L, Sawaki A, et al. Trastuzumab in combination with chemotherapy versus chemotherapy alone for treatment of HER2-positive advanced gastric or gastrooesophageal junction cancer (ToGA): a phase 3, open-label, randomised controlled trial. Lancet. 2010:376(9742):687-97.

2. Schofield L, Grieu F, Goldblatt J, Amanuel B, lacopetta B. A state-wide population-based program for detection of lynch syndrome based upon immunohistochemical and molecular testing of colorectal tumours. Familial Cancer. 2012;11(1):1-6.

3. Toon CW, Walsh MD, Chou A, Capper D, Clarkson A, Sioson L, et al. BRAFV600E immunohistochemistry facilitates universal screening of colorectal cancers for lynch syndrome. Am J Surg Pathol. 2013;37(10): 1592-602.

4. Le DT, Uram JN, Wang H, Bartlett BR, Kemberling H, Eyring AD, et al. PD-1 blockade in tumors with mismatch-repair deficiency. N Engl J Med. 2015; 372(26):2509-20.

5. Owen DR, Wong HL, Bonakdar M, Jones M, Hughes CS, Morin GB, et al. Molecular characterization of ERBB2-amplified colorectal cancer identifies potential mechanisms of resistance to targeted therapies: a report of two instructive cases. Cold Spring Harb Mol Case Stud. 2018.

6. Hudis CA. Trastuzumab--mechanism of action and use in clinical practice. N Engl J Med. 2007;357(1):39-51.

7. Slamon DJ, Leyland-Jones B, Shak S, Fuchs H, Paton V, Bajamonde A, et al. Use of chemotherapy plus a monoclonal antibody against HER2 for metastatic breast cancer that overexpresses HER2. N Engl J Med. 2001; 344(11):783-92.

8. Vogel $\mathrm{CL}$, Cobleigh MA, Tripathy D, Gutheil JC, Harris LN, Fehrenbacher L, et al. Efficacy and safety of trastuzumab as a single agent in first-line treatment 
of HER2-overexpressing metastatic breast cancer. Journal of clinical oncology : official journal of the American Society of Clinical Oncology. 2002;20(3):719-26.

9. Sartore-Bianchi A, Trusolino L, Martino C, Bencardino K, Lonardi S, Bergamo $F$, et al. Dual-targeted therapy with trastuzumab and lapatinib in treatmentrefractory, KRAS codon 12/13 wild-type, HER2-positive metastatic colorectal cancer (HERACLES): a proof-of-concept, multicentre, open-label, phase 2 trial. Lancet Oncol. 2016;17(6):738-46.

10. Bartley AN, Washington MK, Colasacco C, Ventura CB, Ismaila N, Benson AB 3rd, et al. HER2 testing and clinical decision making in gastroesophageal adenocarcinoma: guideline from the College of American Pathologists, American Society for Clinical Pathology, and the American Society of Clinical Oncology. J Clin Oncol. 2017;35(4):446-64.

11. Bertotti A, Migliardi G, Galimi F, Sassi F, Torti D, Isella C, et al. A molecularly annotated platform of patient-derived xenografts ("xenopatients") identifies HER2 as an effective therapeutic target in cetuximab-resistant colorectal cancer. Cancer Discov. 2011;1(6):508-23.

12. Valtorta E, Martino C, Sartore-Bianchi A, Penaullt-Llorca F, Viale G, Risio M, et al. Assessment of a HER2 scoring system for colorectal cancer: results from a validation study. Mod Pathol. 2015;28(11):1481-91.

13. Aparicio T, Svrcek M, Zaanan A, Beohou E, Laforest A, Afchain P, et al. Small bowel adenocarcinoma phenotyping, a clinicobiological prognostic study. Br J Cancer. 2013;109(12):3057-66.

14. Aumayr K, Soleiman A, Sahora K, Schindl M, Werba G, Schoppmann SF, et al. HER2 gene amplification and protein expression in pancreatic ductal adenocarcinomas. Appl Immunohistochem Mol Morphol. 2014;22(2):146-52.

15. Chou A, Waddell N, Cowley MJ, Gill AJ, Chang DK, Patch AM, et al. Clinical and molecular characterization of HER2 amplified-pancreatic cancer. Genome Med. 2013;5(8):78.

16. Galdy S, Lamarca A, McNamara MG, Hubner RA, Cella CA, Fazio N, et al. HER2/HER3 pathway in biliary tract malignancies; systematic review and meta-analysis: a potential therapeutic target? Cancer Metastasis Rev. 2017; 36(1):141-57.

17. Kavuri SM, Jain N, Galimi F, Cottino F, Leto SM, Migliardi G, et al. HER2 activating mutations are targets for colorectal cancer treatment. Cancer Discov. 2015;5(8):832-41.

18. Lee WS, Park YH, Lee JN, Baek JH, Lee TH, Ha SY. Comparison of HER2 expression between primary colorectal cancer and their corresponding metastases. Cancer Med. 2014;3(3):674-80.

19. Overman MJ, Pozadzides J, Kopetz S, Wen S, Abbruzzese JL, Wolff RA, et al. Immunophenotype and molecular characterisation of adenocarcinoma of the small intestine. Br J Cancer. 2010;102(1):144-50.

20. Yoshikawa D, Ojima H, Iwasaki M, Hiraoka N, Kosuge T, Kasai S, et al. Clinicopathological and prognostic significance of EGFR, VEGF, and HER2 expression in cholangiocarcinoma. Br J Cancer. 2008;98(2):418-25.

21. Chan OT, Chen ZM, Chung F, Kawachi K, Phan DC, Himmelfarb E, et al. Lack of HER2 overexpression and amplification in small intestinal adenocarcinoma. Am J Clin Pathol. 2010;134(6):880-5.

22. Zehir A, Benayed R, Shah RH, Syed A, Middha S, Kim HR, et al. Mutational landscape of metastatic cancer revealed from prospective clinical sequencing of 10,000 patients. Nat Med. 2017;23(6):703-13.

23. Assenat E, Azria D, Mollevi C, Guimbaud R, Tubiana-Mathieu N, Smith D, et al. Dual targeting of HER1/EGFR and HER2 with cetuximab and trastuzumab in patients with metastatic pancreatic cancer after gemcitabine failure: results of the "THERAPY"phase 1-2 trial. Oncotarget. 2015;6(14):12796-808

24. Larbouret C, Robert B, Bascoul-Mollevi C, Penault-Llorca F, Ho-Pun-Cheung A, Morisseau S, et al. Combined cetuximab and trastuzumab are superior to gemcitabine in the treatment of human pancreatic carcinoma xenografts. Ann Oncol. 2010;21(1):98-103.

25. Hamad A, Singhi AD, Bahary N, McGrath K, Amarin R, Zeh HJ, et al. Neoadjuvant treatment with Trastuzumab and FOLFOX induces a complete pathologic response in a metastatic ERBB2 (HER2)-amplified duodenal Cancer. J Natl Compr Cancer Netw. 2017;15(8):983-8.

26. Ramanathan RK, Hwang JJ, Zamboni WC, Sinicrope FA, Safran H, Wong MK, et al. Low overexpression of HER-2/neu in advanced colorectal cancer limits the usefulness of trastuzumab (Herceptin) and irinotecan as therapy. A phase II trial. Cancer Investig. 2004;22(6):858-65.

27. Bacher JW, Flanagan LA, Smalley RL, Nassif NA, Burgart LJ, Halberg RB, et al. Development of a fluorescent multiplex assay for detection of MSI-high tumors. Dis Markers. 2004;20(4-5):237-50.
28. Giampieri R, Maccaroni E, Mandolesi A, Del Prete M, Andrikou K, Faloppi L, et al. Mismatch repair deficiency may affect clinical outcome through immune response activation in metastatic gastric cancer patients receiving first-line chemotherapy. Gastric Cancer. 2017;20(1):156-63.

29. Gu MJ, Bae YK, Kim A, Hong SM, Yu E, Kim J, et al. Expression of hMLH1, hMSH2 and hMSH6 in small intestinal carcinomas. Hepatogastroenterology. 2012;59(119):2228-32.

30. Smyth EC, Wotherspoon A, Peckitt C, Gonzalez D, Hulkki-Wilson S, Eltahir Z, et al. Mismatch repair deficiency, microsatellite instability, and survival: an exploratory analysis of the Medical Research Council adjuvant gastric Infusional chemotherapy (MAGIC) trial. JAMA Oncol. 2017;3(9):1197-203.

31. Riazy M, Kalloger SE, Sheffield BS, Peixoto RD, Li-Chang HH, Scudamore $\mathrm{CH}$, et al. Mismatch repair status may predict response to adjuvant chemotherapy in resectable pancreatic ductal adenocarcinoma. Mod Pathol. 2015;28(10):1383-9.

32. Ruemmele P, Dietmaier W, Terracciano L, Tornillo L, Bataille F, Kaiser A, et al. Histopathologic features and microsatellite instability of cancers of the papilla of vater and their precursor lesions. Am J Surg Pathol. 2009;33(5): 691-704.

33. Hinrichsen I, Kemp M, Peveling-Oberhag J, Passmann S, Plotz G, Zeuzem S, et al. Promoter methylation of MLH1, PMS2, MSH2 and p16 is a phenomenon of advanced-stage HCCs. PLoS One. 2014;9(1):e84453.

34. Inada R, Sekine S, Taniguchi H, Tsuda H, Katai H, Fujiwara T, et al. ARID1A expression in gastric adenocarcinoma: clinicopathological significance and correlation with DNA mismatch repair status. World I Gastroenterol. 2015; 21(7):2159-68.

35. Karpinska-Kaczmarczyk K, Lewandowska M, Lawniczak M, Bialek A, Urasinska E. Expression of mismatch repair proteins in early and advanced gastric Cancer in Poland. Med Sci Monit. 2016;22:2886-92.

36. Kawazoe A, Kuwata T, Kuboki Y, Shitara K, Nagatsuma AK, Aizawa M, et al. Clinicopathological features of programmed death ligand 1 expression with tumor-infiltrating lymphocyte, mismatch repair, and Epstein-Barr virus status in a large cohort of gastric cancer patients. Gastric Cancer. 2017:20(3):407-15.

37. Lee HJ, Jang YJ, Lee EJ, Kim JH, Park SS, Park SH, et al. The significance of mismatch repair genes in gastric cancer. J Cancer Res Ther. 2013;9(1):80-3.

38. Xing X, Jia S, Wu J, Feng Q, Dong B, Li B, et al. Clonality analysis of synchronous gastro-oesophageal junction carcinoma and distal gastric cancer by whole-exome sequencing. J Pathol. 2017;243(2):165-75.

39. Farris $A B$ 3rd, Demicco EG, Le LP, Finberg KE, Miller J, Mandal $R$, et al. Clinicopathologic and molecular profiles of microsatellite unstable Barrett esophagus-associated adenocarcinoma. Am J Surg Pathol. 2011; 35(5):647-55.

40. Kulke MH, Thakore KS, Thomas G, Wang H, Loda M, Eng C, et al. Microsatellite instability and $\mathrm{hMLH} 1 / \mathrm{hMSH} 2$ expression in Barrett esophagus-associated adenocarcinoma. Cancer. 2001;91(8):1451-7.

41. Vasavi M, Kiran V, Ravishankar B, Prabhakar B, Ahuja YR, Hasan Q. Microsatellite instability analysis and its correlation with $\mathrm{hMLH1}$ repair gene hypermethylation status in esophageal pathologies including cancers. Cancer Biomark. 2010;7(1):1-10.

42. Le DT, Durham JN, Smith KN, Wang H, Bartlett BR, Aulakh LK, et al. Mismatch repair deficiency predicts response of solid tumors to PD-1 blockade. Science. 2017:357(6349):409-13.

43. Parkes EE, Walker SM, Taggart LE, McCabe N, Knight LA, Wilkinson R, et al. Activation of STING-dependent innate immune signaling by S-phasespecific DNA damage in breast Cancer. J Natl Cancer Inst. 2017;109(1).

44. Brahmer JR, Tykodi SS, Chow LQ, Hwu WJ, Topalian SL, Hwu P, et al. Safety and activity of anti-PD-L1 antibody in patients with advanced cancer. N Engl J Med. 2012;366(26):2455-65.

45. Freeman GJ, Long AJ, Iwai Y, Bourque $K$, Chernova T, Nishimura $H$, et al. Engagement of the PD-1 immunoinhibitory receptor by a novel B7 family member leads to negative regulation of lymphocyte activation. J Exp Med. 2000;192(7):1027-34

46. Herbst RS, Baas P, Kim DW, Felip E, Perez-Gracia JL, Han JY, et al. Pembrolizumab versus docetaxel for previously treated, PD-L1-positive, advanced non-small-cell lung cancer (KEYNOTE-010): a randomised controlled trial. Lancet. 2016;387(10027):1540-50.

47. Meng $X$, Huang Z, Teng F, Xing L, Yu J. Predictive biomarkers in PD-1/PD-L1 checkpoint blockade immunotherapy. Cancer Treat Rev. 2015;41(10):868-76.

48. Hellmann MD, Nathanson T, Rizvi H, Creelan BC, Sanchez-Vega F, Ahuja A, et al. Genomic features of response to combination immunotherapy in 
patients with advanced non-small-cell lung Cancer. Cancer Cell. 2018;33(5): 843-52 e4.

49. Chen K, Cheng G, Zhang F, Zhang N, Li D, Jin J, et al. Prognostic significance of programmed death-1 and programmed death-ligand 1 expression in patients with esophageal squamous cell carcinoma. Oncotarget. 2016;7(21):30772-80.

50. Tsutsumi S, Saeki H, Nakashima Y, Ito S, Oki E, Morita M, et al. Programmed death-ligand 1 expression at tumor invasive front is associated with epithelial-mesenchymal transition and poor prognosis in esophageal squamous cell carcinoma. Cancer Sci. 2017;108(6):1119-27.

51. Zhang W, Pang Q, Zhang X, Yan C, Wang Q, Yang J, et al. Programmed death-ligand 1 is prognostic factor in esophageal squamous cell carcinoma and is associated with epidermal growth factor receptor. Cancer Sci. 2017; 108(4):590-7.

52. Chen L, Xiong Y, Li J, Zheng X, Zhou Q, Turner A, et al. PD-L1 expression promotes epithelial to mesenchymal transition in human esophageal Cancer. Cell Physiol Biochem. 2017;42(6):2267-80.

53. Ma C, Patel K, Singhi AD, Ren B, Zhu B, Shaikh F, et al. Programmed death-ligand 1 expression is common in gastric Cancer associated with Epstein-Barr virus or microsatellite instability. Am J Surg Pathol. 2016; 40(11):1496-506.

54. Gani F, Nagarajan N, Kim Y, Zhu Q, Luan L, Bhaijjee F, et al. Program death 1 immune checkpoint and tumor microenvironment: implications for patients with intrahepatic cholangiocarcinoma. Ann Surg Oncol. 2016;23(8):2610-7.

55. Ma K, Wei X, Dong D, Wu Y, Geng Q, Li E. PD-L1 and PD-1 expression correlate with prognosis in extrahepatic cholangiocarcinoma. Oncol Lett. 2017;14(1):250-6.

56. Fuchs CS, Doi T, Jang RW, Muro K, Satoh T, Machado M, et al. Safety and efficacy of Pembrolizumab monotherapy in patients with previously treated advanced gastric and gastroesophageal junction Cancer: phase 2 clinical KEYNOTE-059 trial. JAMA Oncol. 2018;4(5):e180013.

57. Bang YJ, Kang YK, Catenacci DV, Muro K, Fuchs CS, Geva R, et al. Pembrolizumab alone or in combination with chemotherapy as first-line therapy for patients with advanced gastric or gastroesophageal junction adenocarcinoma: results from the phase II nonrandomized KEYNOTE-059 study. Gastric Cancer. 2019.

58. Herbst RS, Soria JC, Kowanetz M, Fine GD, Hamid O, Gordon MS, et al. Predictive correlates of response to the anti-PD-L1 antibody MPDL3280A in cancer patients. Nature. 2014;515(7528):563-7.

59. Powles T, Eder JP, Fine GD, Braiteh FS, Loriot Y, Cruz C, et al. MPDL3280A (anti-PD-L1) treatment leads to clinical activity in metastatic bladder cancer. Nature. 2014:515(7528):558-62.

60. Davies H, Bignell GR, Cox C, Stephens P, Edkins S, Clegg S, et al. Mutations of the BRAF gene in human cancer. Nature. 2002;417(6892):949-54.

61. Michaloglou C, Vredeveld LC, Mooi WJ, Peeper DS. BRAF(E600) in benign and malignant human tumours. Oncogene. 2008;27(7):877-95.

62. Flaherty KT, Puzanov I, Kim KB, Ribas A, McArthur GA, Sosman JA, et al. Inhibition of mutated, activated BRAF in metastatic melanoma. N Engl J Med. 2010;363(9):809-19.

63. Prahallad A, Sun C, Huang S, Di Nicolantonio F, Salazar R, Zecchin D, et al. Unresponsiveness of colon cancer to BRAF(V600E) inhibition through feedback activation of EGFR. Nature. 2012;483(7387):100-3.

64. Kim KB, Cabanillas ME, Lazar AJ, Williams MD, Sanders DL, llagan JL, et al. Clinical responses to vemurafenib in patients with metastatic papillary thyroid cancer harboring BRAF(V600E) mutation. Thyroid. 2013;23(10):1277-83.

65. Rush S, Foreman N, Liu A. Brainstem ganglioglioma successfully treated with vemurafenib. Journal of clinical oncology : official journal of the American Society of Clinical Oncology. 2013;31(10):e159-60.

66. Baba Y, Ishimoto T, Harada K, Kosumi K, Murata A, Miyake K, et al. Molecular characteristics of basaloid squamous cell carcinoma of the esophagus: analysis of KRAS, BRAF, and PIK3CA mutations and LINE-1 methylation. Ann Surg Oncol. 2015;22(11):3659-65.

67. Blaker H, Helmchen B, Bonisch A, Aulmann S, Penzel R, Otto HF, et al. Mutational activation of the RAS-RAF-MAPK and the Wnt pathway in small intestinal adenocarcinomas. Scand J Gastroenterol. 2004;39(8):748-53.

68. Corso G, Velho S, Paredes J, Pedrazzani C, Martins D, Milanezi F, et al. Oncogenic mutations in gastric cancer with microsatellite instability. Eur J Cancer. 2011;47(3):443-51.

69. Kumagai R, Kohashi K, Takahashi S, Yamamoto H, Hirahashi M, Taguchi K, et al. Mucinous phenotype and CD10 expression of primary adenocarcinoma of the small intestine. World J Gastroenterol. 2015;21(9):2700-10.
70. Masetti M, Acquaviva G, Visani M, Tallini G, Fornelli A, Ragazzi M, et al. Longterm survivors of pancreatic adenocarcinoma show low rates of genetic alterations in KRAS, TP53 and SMAD4. Cancer Biomark. 2018;21 (2):323-34.

71. Preusser M, Berghoff AS, Capper D, von Deimling A, Maroske F, Brodowicz T, et al. No evidence for BRAF-V600E mutations in gastroeosophageal tumors: results from a high-throughput analysis of 534 cases using a mutationspecific antibody. Appl Immunohistochem Mol Morphol. 2013;21(5):426-30.

72. Preusser M, Berghoff AS, Ithan-Mutlu A, Dinhof C, Magerle M, Marosi C, et al. Brain metastases of gastro-oesophageal cancer: evaluation of molecules with relevance for targeted therapies. Anticancer Res. 2013;33(3):1065-71.

73. Tannapfel A, Sommerer F, Benicke M, Katalinic A, Uhlmann D, Witzigmann $\mathrm{H}$, et al. Mutations of the BRAF gene in cholangiocarcinoma but not in hepatocellular carcinoma. Gut. 2003;52(5):706-12.

74. van Grieken NC, Aoyama T, Chambers PA, Bottomley D, Ward LC, Inam I, et al. KRAS and BRAF mutations are rare and related to DNA mismatch repair deficiency in gastric cancer from the east and the west: results from a large international multicentre study. Br J Cancer. 2013;108(7):1495-501.

75. Warneke VS, Behrens HM, Haag J, Balschun K, Boger C, Becker T, et al. Prognostic and putative predictive biomarkers of gastric cancer for personalized medicine. Diagn Mol Pathol. 2013;22(3):127-37.

76. Zuo Q, Huang H, Shi M, Zhang F, Sun J, Bin J, et al. Multivariate analysis of several molecular markers and clinicopathological features in postoperative prognosis of hepatocellular carcinoma. Anat Rec (Hoboken). 2012;295(3):423-31.

77. Goeppert B, Frauenschuh L, Renner M, Roessler S, Stenzinger A, Klauschen F, et al. BRAF V600E-specific immunohistochemistry reveals low mutation rates in biliary tract cancer and restriction to intrahepatic cholangiocarcinoma. Mod Pathol. 2014;27(7):1028-34.

78. Calhoun ES, Jones JB, Ashfaq R, Adsay V, Baker SJ, Valentine V, et al. BRAF and FBXW7 (CDC4, FBW7, AGO, SEL10) mutations in distinct subsets of pancreatic cancer potential therapeutic targets. Am J Pathol. 2003;163(4): 1255-60.

79. Heestand GM, Kurzrock R. Molecular landscape of pancreatic cancer: implications for current clinical trials. Oncotarget. 2015;6(7):4553-61.

80. Schultz NA, Roslind A, Christensen IJ, Horn T, Hogdall E, Pedersen LN, et al. Frequencies and prognostic role of KRAS and BRAF mutations in patients with localized pancreatic and ampullary adenocarcinomas. Pancreas. 2012; 41(5):759-66.

81. Kocsis J, Arokszallasi A, Andras C, Balogh I, Beres E, Deri J, et al. Combined dabrafenib and trametinib treatment in a case of chemotherapy-refractory extrahepatic BRAF V600E mutant cholangiocarcinoma: dramatic clinical and radiological response with a confusing synchronic new liver lesion. J Gastrointest Oncol. 2017;8(2):E32-E8.

82. Lavingia V, Fakih M. Impressive response to dual BRAF and MEK inhibition in patients with BRAF mutant intrahepatic cholangiocarcinoma-2 case reports and a brief review. J Gastrointest Oncol. 2016;6(7):E98-E102.

83. Wainberg ZA, UNL EE, Italiano A, Curigliano G, De Braud FG, Prager G, Greil R, Stein A, Fasolo A, Schellens JHM, Wen PY, Boran AD, Burgess P, Gasal E, Ilankumaran $P$, Subbiah V. Efficacy and safety of dabrafenib (D) and trametinib (T) in patients (pts) with BRAF V600E-mutated biliary tract cancer (BTC): a cohort of the ROAR basket trial. J Clin Oncol. 2019; Abstract 187.

84. Grinshpun A, Zarbiv Y, Roszik J, Subbiah V, Hubert A. Beyond KRAS: practical molecular targets in pancreatic adenocarcinoma. Case Rep Oncol. 2019; 12(1):7-13.

85. Acquaviva J, Wong R, Charest A. The multifaceted roles of the receptor tyrosine kinase ROS in development and cancer. Biochim Biophys Acta. 2009;1795(1):37-52.

86. Rikova K, Guo A, Zeng Q, Possemato A, Yu J, Haack H, et al. Global survey of phosphotyrosine signaling identifies oncogenic kinases in lung cancer. Cell. 2007;131(6):1190-203.

87. Shaw AT, Ou SH, Bang YJ, Camidge DR, Solomon BJ, Salgia R, et al. Crizotinib in ROS1-rearranged non-small-cell lung cancer. N Engl J Med. 2014;371(21):1963-71.

88. Gu TL, Deng X, Huang F, Tucker M, Crosby K, Rimkunas V, et al. Survey of tyrosine kinase signaling reveals ROS kinase fusions in human cholangiocarcinoma. PLoS One. 2011;6(1):e15640.

89. Grossman RL, Heath AP, Ferretti V, Varmus HE, Lowy DR, Kibbe WA, et al. Toward a shared vision for Cancer genomic data. N Engl J Med. 2016; 375(12):1109-12.

90. Bubendorf L, Buttner R, Al-Dayel F, Dietel M, Elmberger G, Kerr K, et al. Testing for ROS1 in non-small cell lung cancer: a review with recommendations. Virchows Arch. 2016;469(5):489-503. 
91. Aisner DL, Nguyen TT, Paskulin DD, Le AT, Haney J, Schulte N, et al. ROS1 and ALK fusions in colorectal cancer, with evidence of intratumoral heterogeneity for molecular drivers. Mol Cancer Res. 2014;12(1):111-8.

92. Hechtman JF, Zehir A, Yaeger R, Wang L, Middha S, Zheng T, et al. Identification of targetable kinase alterations in patients with colorectal carcinoma that are preferentially associated with wild-type RAS/RAF. Mol Cancer Res. 2016;14(3):296-301.

93. Houang M, Toon CW, Clarkson A, Sioson L, de Silva K, Watson N, et al. ALK and ROS1 overexpression is very rare in colorectal adenocarcinoma. Appl Immunohistochem Mol Morphol. 2015;23(2):134-8.

94. Trachu N, Sirachainan E, Larbcharoensub N, Rattanadech W, Detarkom S, Monnamo $\mathrm{N}$, et al. Molecular alterations and clinical prognostic factors for cholangiocarcinoma in Thai population. Onco Targets Ther. 2017;10:4955-68.

95. Yang Y, Wu N, Shen J, Teixido C, Sun X, Lin Z, et al. MET overexpression and amplification define a distinct molecular subgroup for targeted therapies in gastric cancer. Gastric Cancer. 2016;19(3):778-88.

96. Lee J, Lee SE, Kang SY, Do IG, Lee S, Ha SY, et al. Identification of ROS1 rearrangement in gastric adenocarcinoma. Cancer. 2013;119(9):1627-35.

97. Lee KH, Lee KB, Kim TY, Han SW, Oh DY, Im SA, et al. Clinical and pathological significance of ROS1 expression in intrahepatic cholangiocarcinoma. BMC Cancer. 2015;15:721.

98. Chiang NJ, Hsu C, Chen JS, Tsou HH, Shen YY, Chao Y, et al. Expression levels of ROS1/ALK/C-MET and therapeutic efficacy of cetuximab plus chemotherapy in advanced biliary tract cancer. Sci Rep. 2016:6:25369.

99. Freeman DJ, Juan T, Reiner M, Hecht JR, Meropol NJ, Berlin J, et al. Association of K-ras mutational status and clinical outcomes in patients with metastatic colorectal cancer receiving panitumumab alone. Clin Colorectal Cancer. 2008;7(3):184-90.

100. Khambata-Ford S, Garrett CR, Meropol NJ, Basik M, Harbison CT, Wu S, et al. Expression of epiregulin and amphiregulin and $\mathrm{K}$-ras mutation status predict disease control in metastatic colorectal cancer patients treated with cetuximab. J Clin Oncol. 2007;25(22):3230-7.

101. Lievre A, Bachet JB, Le Corre D, Boige V, Landi B, Emile JF, et al. KRAS mutation status is predictive of response to cetuximab therapy in colorectal cancer. Cancer Res. 2006;66(8):3992-5.

\section{Publisher's Note}

Springer Nature remains neutral with regard to jurisdictional claims in published maps and institutional affiliations.

Ready to submit your research? Choose BMC and benefit from:

- fast, convenient online submission

- thorough peer review by experienced researchers in your field

- rapid publication on acceptance

- support for research data, including large and complex data types

- gold Open Access which fosters wider collaboration and increased citations

- maximum visibility for your research: over $100 \mathrm{M}$ website views per year

At $\mathrm{BMC}$, research is always in progress.

Learn more biomedcentral.com/submissions 